\title{
O ENSINO DE HISTÓRIA NOS ANOS INICIAIS: \\ APONTAMENTOS NO PROCESSO DE CONSTRUÇÃO DO \\ CONHECIMENTO HISTÓRICO
}

\begin{abstract}
HISTORY TEACHING FOR CHILDREN FROM INITIAL GRADES: DISCUSSIONS AND CHALLENGES IN THE DEVELOPMENT OF HISTORICAL KNOWLEDGE
\end{abstract}

Eliane Aparecida Candoti ${ }^{1}$

\begin{abstract}
RESUMO: $\mathrm{Na}$ busca por novos campos de estudo no ensino de História, nos deparamos com o conceito de literacia histórica desenvolvido por Peter Lee e seus apontamentos sobre a alfabetização histórica já nos anos iniciais. Vários autores discutem essa temática relacionada à contextualização de vivências locais e configurações identitárias do referido meio, onde se evidencia o desenvolvimento de competências que contribuem para o aprimoramento do pensamento histórico, além de favorecer a elaboração de raciocínios cada vez mais complexos. Percebemos que todo esse processo tem início nas necessidades e indagações apontadas pelo grupo em questão, as quais irão motivar novos olhares sobre diferentes contextos, além de ações investigativas sobre os mesmos.
\end{abstract}

Palavras-chaves: Educação histórica. Literacia histórica. Identidades, contextualização.

ABSTRACT: Looking for new fields of study in history teaching, we come across with the concept of historical literacy developed by Peter Lee and his appointments about historical literacy in the initial grades. Several authors discuss the questions related to the contextualization of local experiences and identity configurations of the related field, where we can see the development of competences that contribute to the improvement of historical and complex way of thinking. We realize that all the process starts with the necessities and questions pointed by the group, these questions motivate new views about different contexts, besides the investigative actions about them.

Keywords: Historical education. Historical literacy. Identities. Contextualization.

\footnotetext{
${ }^{1}$ Professora da rede pública de ensino do Estado do Paraná. Mestranda História social UEL.
} 


\section{Introdução}

O presente artigo trata do ensino de História nos anos iniciais do Ensino Fundamental, abordando a importância da educação histórica e da utilização das narrativas a fim de proporcionar uma aprendizagem significativa por meio do contexto local.

Iniciamos o texto com as menções dos autores Katia Abud, Circe Bittencourt, Marcos Silva e Selva Guimarães Fonseca a cerca do currículo escolar no ensino de História, apontando-o enquanto elemento chave no processo de construção do conhecimento histórico, uma vez que este estabelece conteúdos e metodologias a serem contemplados pelo professor em sala de aula. Os autores destacam que o conhecimento histórico deve estar relacionado com a realidade da comunidade escolar, de modo que as vivências locais sejam contextualizadas, além de abranger saberes e configurações identitárias excluídos até então. De acordo com os mesmos trata-se de agregar significado à proposta curricular possibilitando por meio dela uma leitura do meio em que os alunos se inserem, bem como a compreensão e valorização das diversidades que o caracterizam.

No que se referem à educação histórica, os autores Jörn Rüsen, Peter Lee, Lana Mara de Castro Siman, Marlene Cainelli e Hilary Cooper discorrem sobre a utilização de elementos de memória significativos ao grupo em questão, a fim de pensar o passado e fazer novas leituras sobre ele, favorecendo assim, a elaboração do pensamento histórico. Rüsen destaca a importância do desenvolvimento da consciência histórica em meio ao processo de pensar o passado e fazer inferências sobre ele, enquanto os demais autores, apoiados em suas pesquisas, evidenciam uma alfabetização histórica que ocorra no início da escolaridade, possibilitando por meio da ação mediadora do professor, que estes se remetam ao passado e façam novas leituras sobre o mesmo. Nesse contexto, como diz Cainelli (2006), Husbands utiliza-se das narrativas para contribuir com a elaboração do pensamento histórico, pois, à medida que os alunos se deparam com diferentes relatos e objetos que 
tratem do passado, raciocínios mais elaborados e novas narrativas surgem a partir de suas análises.

Apoiamo-nos nas pesquisas desses autores para pensar a respeito do ensino de História nos anos iniciais do Ensino Fundamental, uma vez que ainda são poucas as produções que contemplam o ensino de História para crianças, lembrando que para tanto é preciso retomar alguns aspectos da organização curricular da disciplina de História e em seguida dar início as discussões.

\section{Educação histórica nos anos iniciais do ensino fundamental}

A trajetória da disciplina de História revela um caráter nacionalista em sua gênese na França do século XIX, uma vez que sua implantação nas escolas remontava à necessidade de uma identidade nacional e da sacralização do poder monárquico. Do mesmo modo como foi idealizada também passou a ser vigiada, pois seus argumentos poderiam promover reflexões e discussões entre os alunos, levando-os a contestar a ordem vigente, o que Santos (2009, p.19) confirma em sua obra ao dizer que, "[...] as autoridades não demoraram muito a entender que a utilização da História no ensino era perigosa, pois estudar o passado poderia fazer os alunos questionarem fatos já consagrados no passado e, principalmente no presente".

Como reflexo dessa preocupação, observamos que os conteúdos presentes no currículo escolar, bem como a sua fundamentação teórica e metodológica, representaram e ainda representam um importante instrumento ideológico nas mãos de diferentes segmentos políticos e sociais, entendendo que o currículo configurou-se enquanto elemento norteador na produção do conhecimento histórico escolar e na formação do indivíduo, tornando-se o alvo de inúmeras reformas educacionais. (ABUD, 1995).

Abud (1995) destaca a importância da associação entre o conhecimento histórico produzido e a realidade da comunidade escolar, a qual é significativa no processo de construção do conhecimento histórico e na formação identitária dos 
envolvidos, uma vez que é capaz de promover a valorização do cotidiano e da participação social dos mesmos.

Entendemos que a seleção de conteúdos escolares e metodologias a fim de compor a proposta curricular é um grande desafio para os professores de História que atendem alunos de diferentes realidades socioculturais. Bittencourt (2004) aponta que, diante da impossibilidade de ensinar "toda história" e das necessidades e anseios das novas gerações, os professores tem optado por diversificar os conteúdos agregando temas significativos à proposta. Uma escolha frequente tem sido elementos que se remetam ao cotidiano e a história de vida dos alunos, os quais possibilitam a contextualização da vivência dos mesmos e das histórias pessoais em meio à coletividade.

Deste modo, abordar a história local nos conduz às memórias escritas ou recuperadas pela oralidade, além de lugares de memória (públicos ou privados). Estes possibilitam o estudo das transformações realizadas por pessoas comuns e a compreensão do entorno sociocultural dos indivíduos, dando visibilidade aos "anônimos da história". Ao relacionar aspectos do passado ainda presentes nos espaços de convívio temos a identificação e a valorização identitária dos alunos. Sendo assim, a memória apresenta-se como base da identidade, pois é por meio dela que chegamos à história local, o que destaca a importância de uma história que estabeleça vínculos com a família, a comunidade, o meio profissional e de lazer. (BITTENCOURT, 2004).

Quanto a isso, os autores Silva e Fonseca apontam que o professor encontrase num contexto multicultural e, portanto, deve ir além do saber especializado presente na organização curricular, promovendo a inserção de contextos específicos, de sujeitos e saberes excluídos. Destacam como função da educação, o desenvolvimento social, devendo "[...] valorizar permanentemente, na ação curricular, as vozes dos diferentes sujeitos, o diálogo, o respeito à diferença, o combate à desigualdade e o exercício da cidadania." (2007, p.55), o que evidencia a necessidade de uma História viva que possa interagir com os elementos de memória 
do meio em que se insere o aluno, sem perder as especificidades do conhecimento histórico.

Deste modo, repensar os conteúdos no ensino de História tem instigado os profissionais dessa área, principalmente diante do descaso de muitos quanto às vivências que os antecedem, ocasionando a desvalorização do contexto pessoal e uma total falta de identidade. Entendemos que estes fatores, bem como as exigências do mundo contemporâneo, nos direcionam para conhecimentos mecânicos e muitas vezes desumanizados, os quais influenciam negativamente as nossas escolhas, repercutindo na falta de cidadania e humanidade diante das situações de conflito e decisão. Como apresentar ações de valorização e preservação de algo que desconhecemos e com o qual não estabelecemos vínculos?

Quando mencionamos a presença de conteúdos mais significativos aos nossos alunos, nos remetemos à proximidade com suas vivências e elementos da história local, de modo que apresentem uma relação com os mesmos, promovendo o desenvolvimento de uma consciência histórica além de outro olhar e uma nova postura frente às diversidades do nosso tempo, motivando-os no processo de busca e construção do conhecimento histórico.

Rüsen (2001) afirma que o ensino de História tem como objetivo o desenvolvimento da consciência histórica nos indivíduos, uma vez que o raciocínio elaborado com a finalidade de entender as ações individuais e coletivas num contexto de tempo e espaço dão condições para que estes se orientem em sua vida prática no tempo presente. $O$ autor parte da importância de viabilizar pensamento histórico por meio de reflexões a respeito das vivências cotidianas do grupo em questão, abordando as mudanças e as permanências, bem como as suas razões no decorrer do tempo. Esse processo, além de contribuir para a compreensão de mundo também contribui para a formação de novos olhares sobre o meio e as questões que se apresentam.

Nesse contexto, Lee (2006) aponta para uma alfabetização histórica que ocorre desde os anos iniciais da formação escolar. Este processo corresponde ao desenvolvimento da capacidade de ler o mundo no qual nos inserimos, partindo de situações concretas do passado que possibilitem a compreensão do mesmo, uma 
vez que a temporalidade histórica é complexa e abstrata. O autor destaca a importância de objetos, lugares e narrativas que permitam a materialização do passado no tempo presente, possibilitando que as crianças se remetam a diferentes temporalidades e contextos históricos. Trata-se de proporcionar situações de aprendizagem que envolvam elementos históricos e cotidianos, lembrando que "nossos interesses dirigem nossa compreensão histórica, a qual, por sua vez, permite que nos orientemos no tempo". Além de agregar significado ao ensino de História, esta prática permite o desenvolvimento de competências de análise e interpretação de fontes diversas, promovendo um conhecimento mais amplo do passado e suas relações com questões presentes e cotidianas, não permanecendo apenas na aquisição de fatos passados, o que também contribui para a formação da consciência histórica e do senso de identidade, bem como a valorização da mesma, estabelecendo relações mais humanizadas entre os seus grupos de convívio e as mais diversas representações socioculturais, ensinando a História, mas principalmente o pensar historicamente.

As autoras Siman (2004) e Cainelli (2006), compartilhando dessa mesma abordagem, evidenciam a educação histórica e a ação mediadora do professor no processo de construção do conhecimento histórico envolvendo crianças do Ensino Fundamental (entre 7 e 9 anos).

Siman (2004) define os professores enquanto mediadores culturais, cuja prática é de extrema importância no processo de construção do conhecimento histórico. De acordo com a autora, é necessário que este promova a relação entre o conhecimento a ser apropriado e as representações que os alunos já trazem viabilizando uma aprendizagem significativa. É interessante quando esta se remete ao laboratório do historiador como sendo imaginário, uma vez que não podemos reproduzir fielmente o que já foi vivido, mas por meio de objetos, documentos, lugares e fontes variadas, temos acesso ao passado e este é materializado a medida que imaginamos circunstâncias e possibilidades de uso de determinados objetos e espaços, de modo que estes objetos e demais elementos classificam-se enquanto objetos mediadores do saber histórico. 
Cainelli (2006) já os classifica como objetos geradores, por meio dos quais fatos, processos e ideias são sugeridos ao mesmo tempo em que reflexões sobre o contexto que envolve os objetos e seus sujeitos são motivadas, promovendo o conhecimento a partir das experiências vividas. De acordo com a autora, esse contato possibilita um diálogo entre a história do objeto e a história da criança.

As autoras concordam que situações de aprendizagem que agregam elementos mediadores (sejam eles de cultura material ou imaterial), permitem uma alfabetização histórica e cultural contribuindo para o desenvolvimento do raciocínio histórico, além de possibilitar às crianças (re)significar o conhecimento à medida que ampliam suas investigações, fazem suas reflexões, imaginam e reconstroem o que não viveram, e assim, constroem o conhecimento histórico, lembrando que a mediação do professor entre os alunos e a temática se dá por meio da observação dos objetos e das indagações que guiam a mesma, de modo que estes sejam representações do contexto.

Cainelli (2006) faz referência à noção de temporalidade desenvolvida pelas crianças a partir da utilização de objetos mediadores no processo de construção do conhecimento histórico. As discussões sobre os mesmos permite que identifiquem características do tempo passado e do tempo presente, destacando mudanças e permanências, pois o modo como as crianças entendem a passagem do tempo está relacionado com a experiência familiar e com a sociedade em que vivem. De acordo com a autora (2010), o contato com a história local nas séries iniciais é extremamente significativo para que ocorra a aprendizagem histórica, uma vez que esta representa a "[...] possibilidade de desenvolver na criança a capacidade de se articular com o seu mundo a partir do seu entorno $[\ldots] "$, permitindo assim, o desenvolvimento de condições para a apreensão do conhecimento histórico.

Outro fator importante no desenvolvimento do pensamento histórico estaria relacionado ao levantamento de hipóteses. E principalmente não ensinar história como repetição mecânica, mas como experiências únicas complexas que constituíram a perspectiva de um ensino consciente em História. (CAINELLI, 2010, p.25) 
Desse modo, a análise e a discussão a cerca dos objetos mediadores e temáticas relacionadas possibilita o levantamento de hipóteses sobre os mesmos e seus contextos, principalmente se estes se referem à história local, o que incorre no desenvolvimento do pensamento histórico. Por sua vez, este pensamento histórico articulado com o conhecimento prévio de cada criança por meio do que the é significativo, permite que a mesma realize suas inferências. Assim, temos a construção do conhecimento histórico enquanto aprendizagem significativa e não apenas um processo de assimilação.

De acordo com Cooper (2006, p. 173-174),

Se quisermos ajudar nossos alunos a se relacionarem ativamente com o passado, precisamos encontrar formas de ensiná-los, desde o começo, que iniciem o processo com eles e seus interesses, que envolvam uma "aprendizagem ativa" e pensamento histórico genuíno, mesmo que embrionário, de maneira crescentemente complexa.

Cooper aponta que as bases do pensamento histórico podem e devem ser estabelecidas nos anos iniciais de escolaridade da criança, pois a capacidade de pensar e argumentar sobre a ação dos sujeitos no tempo e no espaço se desenvolve mediante a utilização de fontes e objetos mediadores, juntamente com a ação mediadora do professor e sendo assim, elementos como identidade, temporalidade e capacidade de refletir sobre as mudanças e permanências tem suas complexidades ampliadas gradativamente, o que a autora confirma ao dizer que,

O processo de investigação histórica envolve a compreensão de conceitos do tempo: a mensuração do tempo, continuidade e mudança, as causas e efeitos de eventos e de mudanças ao longo do tempo, semelhanças e diferenças entre períodos. Isso significa encontrar o passado a partir de fontes, os traços do passado que permanecem, sejam escritos, visuais ou orais. (2006, p. 175)

Para tanto é preciso aliar ludicidade e cotidiano à temporalidade e conhecimento histórico fazendo com que a história ganhe vida e significado, uma vez que se trata de uma construção abstrata. A diversidade de fontes e abordagens juntamente com esses elementos permite que a criança circule entre o real e o imaginário por meio de narrativas literárias ou construídas, objetos e vivências, 
lembrado que a apropriação e ressignificação da mesma se dá de modo concreto, ou seja, quando esta pode ser visualizada, lida, contada ou vivenciada, a fim de que a criança possa imaginar e relacionar contextos passados e presentes. Nessa perspectiva torna-se capaz de elaborar hipóteses sobre o que não existe mais e questionar o conhecimento que dispõe sobre o presente, para então realizar suas inferências e assim produzir o conhecimento histórico.

\section{Possibilidades de construção da literacia histórica}

Nosso enfoque nesses autores deve-se à relevância das discussões sobre o ensino de História nas séries iniciais do Ensino Fundamental, uma vez que as bases do processo de formação do indivíduo se constituem nesse período. Trata-se de

uma proposta voltada ao desenvolvimento de competências que favoreçam o pensamento histórico enquanto as temáticas curriculares são trabalhadas, de modo que os conceitos e embasamentos necessários para abordagens mais complexas desenvolvam-se nesse primeiro momento e aprimorem-se à medida que ocorre a ampliação dos estudos e novos posicionamentos frente aos desafios.

Percebemos que recentemente a academia tem se voltado de modo especial para a área de ensino, lembrando que por muito tempo, mesmo nos cursos de licenciatura, pesquisa e ensino receberam tratamentos distintos, como se não estivessem intrinsecamente ligados. Apontamos esta área como dorso central no processo de formação dos indivíduos que ingressam na academia e seguem como pesquisadores ou como educadores, uma vez que pesquisa e ensino são inerentes à prática do historiador.

Os autores referendados no decorrer do texto discutem uma educação histórica, a qual propõe uma organização curricular significativa aos nossos alunos, sendo capaz de dialogar com outras áreas do conhecimento. Trata-se de pensar o passado, matéria prima da história, a partir de elementos que se articulem com os conceitos e aspectos cotidianos dos alunos por meio de situações que favoreçam um raciocínio mais elaborado sobre o objeto de estudo. 
Quando abordamos a produção do pensamento histórico nas séries/anos iniciais a partir de elementos concretos, possibilitando aos alunos revisitar, repensar e rediscutir a História passada e presente proporcionamos situações de aprendizagem que viabilizam a realização de inferências por parte dos mesmos e assim chegamos às construções coletivas e individuais do conhecimento histórico, além de instiga-los à prática da pesquisa.

Ao indagar os alunos do $4^{\circ}$ ano do Ensino Fundamental (E.M. Santos Dumont/ 2013 em Londrina) sobre o desenvolvimento de uma pesquisa sobre a história local a partir de acervos fotográficos e de objetos familiares, os mesmos relataram sobre o prazer em descobrir a história de Londrina por meio das pesquisas bibliográficas e entrevistas, além do contato com objetos, fotos e narrativas presentes na família. Alguns alunos se referiram de modo curioso às narrativas obtidas por meio dos depoimentos, destacando que ao analisarem as mesmas perceberam que estas constituíram um texto com informações semelhantes às do livro didático e que a pesquisa os ajudou a conhecer mais sobre o bairro e a cidade, bem como sobre as pessoas que vivem nesses espaços. Enquanto explicavam o assunto da referida pesquisa e apontavam os objetos presentes na exposição refaziam suas narrativas conforme a compreensão das temáticas abordadas. Durante uma entrevista com um dos primeiros moradores do bairro, por várias vezes fizeram perguntas evidenciando a preocupação com as mudanças e permanências no cotidiano da comunidade, bem como as expectativas sobre o futuro, enfatizando os fatores que contribuíram para a realidade que conhecem.

De acordo com as pesquisas já mencionadas, podemos detectar na experiência desses alunos a elaboração do pensamento histórico orientado pela mediação da professora que promoveu uma aprendizagem histórica significativa, articulando a diversidade de fontes e narrativas relacionadas à história local.

Ensinar história nas séries iniciais na perspectiva de proporcionar aos alunos se entenderem no tempo em que vivem a partir do entendimento dos sujeitos de outros tempos e lugares pressupõe a 
possibilidade da compreensão desta história através da narrativa. (CAINELLI, 2010, p. 29)

Em seu texto, Cainelli (2010) se apoia nas ideias do autor Chris Husbands (apud CAINELLI, 2010, p.29) ao abordar a importância da utilização de narrativas históricas no processo de construção do conhecimento histórico. Para Husbands as narrativas escolares representam o modo pelo qual alunos e professores se reportam ao passado histórico de modo significativo quando analisam e produzem versões diferentes sobre o mesmo. O fato de possibilitar o confronto de diferentes narrativas envolvendo sujeitos, ações e temporalidades distintas, promove um exame mais crítico de situações identitárias e cotidianas enquanto compreendem o contexto e constroem suas próprias narrativas.

Destacamos a fala desses autores para enfatizar a importância da utilização das narrativas no ensino de história, uma vez que estas são extremamente significativas no desenvolvimento do pensamento histórico e da criticidade enquanto nos remetemos ao passado e discutimos as ideias de causa, continuidade e mudança.

Apoiados na fala de Pierre Villar (1985), o qual afirma que "compreender é impossível sem conhecer" e nos demais autores já relacionados, nos motivamos a referenciar a educação histórica, bem como a utilização das narrativas no ensino de história nos anos iniciais do ensino fundamental, como elementos essenciais na formação da consciência histórica nos indivíduos. Relacionamos esta proposta como um ensino de história significativo e eficiente, uma vez que promove a compreensão de diferentes temporalidades e realidades valorizando as mesmas. Quando citamos Villar (1985) referenciamos a importância de uma aprendizagem histórica que se articule com aspectos da história local e das identidades que a compõem, utilizando-a enquanto ponte para pensar o passado. Precisamos conhecer a nossa realidade para compreender as especificidades e diversidades presentes na sociedade, ao passo em que temos o nosso olhar reeducado para analisar e inferir sobre diferentes contextos promovendo novas leituras da História e seus sujeitos, além de ações mais humanizadas na prática da cidadania. 


\section{Considerações finais}

De acordo com as Diretrizes Curriculares para o Ensino Fundamental de nove anos (2010), cabe ao ensino de História promover entre os alunos a compreensão do seu ambiente social, do sistema político e dos valores em que se fundamenta a sociedade, partindo dos sujeitos e suas ações no tempo e no espaço.

Quanto a isso, nos voltamos à prática da educação histórica, uma vez que esta conduz ao aprimoramento do olhar do aluno para suas questões cotidianas, bem como para as articulações sociais que dão no entorno e das quais também faz parte.

Entendemos que esta proposta corresponde a um processo de alfabetização histórica, sendo capaz de desenvolver a consciência histórica nos indivíduos à medida que parte de elementos identitários e cotidianos, os quais tornam o ensino de história um processo significativo de construção contínua do conhecimento.

Quando os alunos avançam para a segunda fase do ensino fundamental ou quando ingressam no ensino médio, percebemos em várias ocasiões, a dificuldade em compreender os processos sociais, bem como elementos de mudança e continuidade presentes em diferentes contextos e temporalidades. Se o ensino de História é um direito garantido desde o ciclo de alfabetização, temos que repensar as razões que contribuem para essas deficiências de aprendizagem.

Nos anos iniciais, discussões sobre a apropriação dos códigos linguísticos e matemáticos em detrimento das demais áreas do conhecimento são frequentes na prática da sala de aula, no entanto, novos encaminhamentos tem se dado no campo da alfabetização, propondo que as áreas de história, geografia, ciência e arte sejam tomadas como elementos geradores por meio dos quais ocorre o ensino de língua portuguesa e matemática. Não se trata apenas de uma proposta interdisciplinar, mas de entender o valor de todas as áreas no processo de formação do indivíduo como um todo, tornando-o capaz de ler e compreender diferentes fontes e 
contextos, percebendo os sujeitos e suas ações como frutos do seu tempo, além de promover a prática da cidadania.

Pensar o ensino de História no ciclo de alfabetização significa contemplar mais do que conteúdos, trata-se de pensar uma numa prática que promova a pesquisa como elemento norteador do currículo, pois entendemos que por meio dos questionamentos feitos ao passado a fim de respondermos problemáticas atuais, temos o desenvolvimento da consciência histórica, além de competências que contribuem para a compreensão das particularidades existentes no tempo histórico. Não se trata de excluir os conteúdos e sua importância, mas de instigar novos olhares ao passado, destacando no mesmo, suas ligações com o presente, além de distinguir transformações e continuidades em meio às construções humanas.

Sendo assim, o que deve ser abordado no ensino de História a fim de atendermos a esta proposta? Acreditamos que a história deva ser percebida nas vivências e nos espaços cotidianos, elementos que possuem ligações com o indivíduo, de modo que ao conhecê-los sob uma nova ótica, possa também fortalecer os seus laços com os mesmos, além de motivar-se na busca de novas fontes e construções do conhecimento. Com o desenvolvimento dessas percepções, proporcionamos aos nossos alunos a capacidade de ler a própria realidade entendendo as tramas presentes e suas relações com o passado, percebendo as razões das mesmas, por meio de uma aprendizagem significativa e dinâmica. Para tanto destacamos o trabalho envolvendo eixos estruturantes como identidades, tempo, memórias, cotidiano e cidadania, o qual se torna significante quanto à formação das bases para a compreensão das temáticas que se apresentam durante a segunda fase do Ensino Fundamental e Ensino Médio.

No entanto, queremos lembrar que o ensino de História não deve se restringir aos anos iniciais do Ensino Fundamental, pois à medida que o indivíduo torna-se capaz de raciocínios cada vez mais elaborados é importante que as discussões em torno da identidade local sejam aprofundadas, situando esse contexto em meio aos conflitos de ordem nacional e mundial. Noções de simultaneidade, mudança e continuidade são significativas no processo de contextualização dos fatos, porém são complexas em função da abstração que as caracteriza, uma vez que a 
compreensão de diferentes processos exige certo grau de reflexão. Sendo assim, a proposta de educação histórica pode estar presente em todos os anos do ensino básico de modo que, ao abordar as ações humanas em diferentes temporalidades, possamos proporcionar aos alunos a ampliação de sua visão de mundo, bem como da criticidade em torno de diferentes contextos e desafios presentes na contemporaneidade.

Dentre esses desafios nos deparamos com a desvalorização dos elementos de memória e passado, uma vez que estes são apontados como oposição à imagem de progresso. Diante disso nos voltamos à necessidade de promover um novo olhar sobre as memórias locais (coletivas e individuais), além de aspectos significativos ao grupo. Para valorizarmos e pensarmos sobre a cotidianidade, salientamos a importância de conhecer sobre ela, retomando as próprias origens e especificidades, o que acaba culminando no desenvolvimento de ações de salvaguarda para com as construções históricas e culturais do seu tempo, bem como sobre os sujeitos envolvidos. Conhecer e valorizar as identidades sociais pode promover no indivíduo uma nova postura diante dos conflitos que se apresentam, além de reflexões com maior complexidade sobre as suas responsabilidades enquanto sujeito histórico. Pensar historicamente nos permite conhecer um pouco mais sobre a vida e suas pluralidades numa perspectiva mais humana.

O que nos motiva a olhar para o passado e a pensar historicamente se não as indagações e inquietações que se apresentam em nossas vidas? São elas que dão sentido à pesquisa e ao aprendizado histórico.

Assim como nos deparamos com a multiplicidade de indivíduos e contextos, também nos deparamos com a diversidade de fontes que emanam dos mesmos (acervos fotográficos, depoimentos, objetos, documentos, entre outros) e que são capazes de configurar quadros, personagens e tramas que já não existem mais, e que muito nos esclarecem em nosso processo de busca e construção do conhecimento. Entre os muitos caminhos nessa proposta, nos conduzimos à história local e consequentemente às memórias escritas ou recuperadas pela oralidade, além dos lugares de memória (públicos ou privados). Estes nos possibilitam o 
estudo das transformações realizadas por homens comuns, a compreensão do próprio entorno, além de outros, relacionando-o com aspectos do passado e ainda presentes nos espaços de convívio.

De acordo com ALBERTI (2005), as fontes orais são um caminho interessante para se conhecer e registrar diferentes experiências e modos de vida na multiplicidade dos grupos sociais, entendendo que os dados coletados em uma entrevista não constituem uma fonte a ser interpretada e analisada, mas em um instrumento de ampliação da consciência histórica da comunidade em questão, possibilitando o conhecimento de novas histórias de vida, a visibilidade de um contexto social mais amplo e a legitimidade de grupos marginalizados, reforçando as identidades, de modo que esses relatos e suas subjetividades contribuem para a compreensão das coletividades.

Entendemos que proporcionar o contato com a variedade de elementos e narrativas por meio da ação investigativa de alunos e professores agrega sentido ao processo de ensinar e aprender História, enquanto possibilita o contato com a diversidade de grupos, a elaboração das próprias impressões e o desenvolvimento do pensamento histórico. Também evidenciamos que todo esse processo não deve se restringir apenas ao ambiente de sala de aula, mas pode ir além dos muros da escola. Proporcionar situações de aprendizagem que permitam ir a campo buscando imagens, lugares e sujeitos que retratem diferentes temporalidades e contextos socioculturais, amplia as possibilidades que o indivíduo tem de se deslocar no tempo e assim realizar suas inferências, o que contribui para a compreensão das diversidades e dos conflitos que caracterizam o seu tempo, instigando nesse meio, suas ações e reflexões enquanto sujeito histórico.

Esclarecemos que estes argumentos se constituíram a partir de várias leituras e observações realizadas no espaço da sala de aula, de modo que não podemos afirmar a existência de um único caminho em busca de soluções para os problemas gerados na ausência de uma consciência histórica e identitária, mas que estes apontamentos têm a pretensão de lançar novos questionamentos sobre o ensino de História nos anos iniciais do Ensino Fundamental. Mais do que certezas temos pontos de partida, por meio dos quais pretendemos ampliar nossas pesquisas no 
âmbito da educação histórica e suas repercussões em meio às ações e produções socioculturais, além de repensar a nossa prática no processo de aprendizagem e construção do conhecimento histórico. Quanto ao ponto de chegada, precisamos definir a luz da realidade dos grupos com os quais convivemos e aos quais atendemos, no entanto o que realmente contribuirá para o nosso êxito, será percurso que escolhermos e o modo como iremos realizá-lo, uma vez que as construções e as mudanças se darão no decorrer dessa caminhada.

\section{Referências}

ABUD, K. M. Conhecimento Histórico e Ensino de História: a produção do conhecimento histórico escolar. In SCHMIDT, M. A. e CAINELLI, M. R. (Org.). II Encontro Perspectivas do Ensino de História. Curitiba: Aos Quatro Ventos, 1995, p.149-156.

. Processos de construção do saber histórico escolar. História \& Ensino.

Londrina: EDUEL, v.11, jul. 2005.

ALBERTI, V. Fontes Orais: Histórias dentro da História. In PINSKY, C. B. (Org.). Fontes históricas. São Paulo: Contexto, 2005.

BITTENCOURT, C. M. F. Ensino de História: fundamentos e métodos. São Paulo: Cortez, 2004.

BRASIL. Secretaria de Educação Básica. Diretoria de Apoio à Gestão Educacional. Pacto nacional pela alfabetização na idade certa: a organização do planejamento e da rotina no ciclo de alfabetização na perspectiva do letramento: ano 2: unidade 2/ Ministério da Educação, Secretaria de Educação Básica, Diretoria de Apoio à Gestão Educacional. Brasília: MEC, SEB, 2012.

CAINELLI, M. Educação Histórica: perspectivas de aprendizagem da história no ensino fundamental. Educar. Especial. Curitiba: Ed. UFPR, 2006, p. 57-72. O que se ensina e o que se aprende em História. História: ensino fundamental. OLIVEIRA, M. M. D. de (Coord.). Brasília: Ministério da Educação, Secretaria de Educação Básica, 2010. (Coleção Explorando o Ensino; v. 21)

COOPER, H. Aprendendo e ensinando sobre o passado a crianças de três anos. Educar. Especial.Curitiba: Ed. UFPR, 2006, p. 171-190. 
FURET, F. O Nascimento da História. In A oficina da História. Trad. Adriano Duarte Rodrigues. Lisboa: Gradativa, v.1, s/d.

LEE, P. Em direção a um conceito de literacia histórica. Educar. Especial. Curitiba: Ed. UFPR, 2006, p. 131-150.

OLIVEIRA, S. R. F. de. História. In AMARAL, A. C. T. do; CASAGRANDE, R. C. de B.; CHULEK, V. (Org.). PARANÁ. Secretaria de Estado de Educação do Paraná. Ensino fundamental de nove anos: orientações pedagógicas para os anos iniciais. Curitiba: Secretaria de Estado de Educação do Paraná, 2010.

RÜSEN, J. Razão Histórica: teoria da História: fundamentos da ciência histórica. Tradução de Estevão de Rezende Martins. Brasília: Ed. Universidade de Brasília, 2001.

SANTOS, A. F. dos. Entre Fatos e Artefatos: literatura e ensino de História nos encontros acadêmicos nacionais (1979-2007). 2009. Dissertação (Mestrado em História Social) - Universidade Estadual de Londrina, Londrina, 2009.

SILVA, M.; FONSECA, S. G. Ensinar História no século XXI: em busca do tempo entendido. Campinas, SP: Papirus, 2007.

SIMAN, L. M. de C. O papel dos mediadores culturais e da ação mediadora do professor no processo de construção do conhecimento histórico pelos alunos. In ZARTH, P. A. (Org.). Ensino de História e Educação. Ijuí: Ed. UNIJUI, 2004.

VILAR, P. Iniciação ao vocabulário de análise histórica. Lisboa, Edições São José da Costa: 1985.

Recebido em 17 de outubro de 2013.

Aprovado em 20 de março de 2014. 